\title{
$\checkmark$ Treatment of Aneurysms in Persistent Primitive Trigeminal Arteries with Stent-Assisted Coil Embolization
}

Shota Sakai, Taketo Hatano, Mitsushige Ando, Hideo Chihara, Takenori Ogura, Keita Suzuki, Keitaro Yamagami, Daisuke Kondo, Takahiko Kamata, Eiji Higashi, Hiroki Sakamoto, and Izumi Nagata

Objective: Persistent primitive trigeminal artery (PPTA) is a rare condition in which a fetal carotid-basilar anastomosis persists into adulthood. PPTA aneurysms often necessitate endovascular treatment and adjunctive techniques, such as stent- or balloon-assisted techniques, are sometimes selected. This case report describes two women in their sixties with unruptured right PPTA aneurysms who underwent stent-assisted coil embolization procedures, with consideration of the anatomical features in each case.

Case Presentations: One patient presented with an aneurysm at the bifurcation of the PPTA and the basilar artery (BA), which was classified as Saltzman type 1 with a hypoplastic vertebral artery (VA)-BA system. A stent was deployed from the BA to the PPTA to cover the neck of the aneurysm and coil embolization was performed. The second patient presented with an aneurysm at the bifurcation of the PPTA and the internal carotid artery (ICA), which was classified as Saltzman type 2 with a hypoplastic VA-BA system. A stent was deployed from the PPTA to the petrous segment of the ICA covering the neck of the aneurysm and coil embolization was performed. In both patients, the 1-year follow-up digital subtraction angiography (DSA) showed that the aneurysms had not recurred.

Conclusion: The PPTA aneurysms were successfully treated with stent-assisted coil embolization. The treatment strategy should be devised in accordance with both the lesion site and the PPTA variant.

Keywords > persistent primitive trigeminal artery, aneurysm, stent, coil embolization

\section{Introduction}

A persistent primitive trigeminal artery (PPTA) occurs when an artery that enables blood flow between the internal carotid artery (ICA) and the basilar artery (BA) during embryonic development persists into adulthood. With a reported prevalence of $0.1 \%-0.6 \%$ in adults, ${ }^{1,2)}$ PPTA is a rare form of anastomosis, although it is the most common persistent fetal form of carotid-basilar anastomosis.

$\overline{\text { Department of Neurosurgery, Kokura Memorial Hospital, Kita- }}$ kyushu, Fukuoka, Japan

Received: March 4, 2020; Accepted: July 22, 2020

Corresponding author: Shota Sakai. Department of Neurosurgery, Kokura Memorial Hospital, 3-2-1, Asano, Kokurakita-ku, Kitakyushu, Fukuoka 802-8555, Japan

Email:shoooo0725@gmail.com

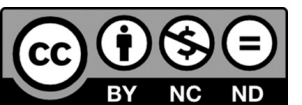

This work is licensed under a Creative Commons Attribution-NonCommercialNoDerivatives International License.

C2021 The Japanese Society for Neuroendovascular Therapy
PPTAs frequently contain aneurysms; aneurysm rupture leads to subarachnoid hemorrhage, while a mass effect of the aneurysm on the trigeminal nerve leads to trigeminal neuralgia. Because the aneurysms are often deeply positioned, endovascular therapies are the first-choice therapies, and the operator must consider the lesion site and PPTA subtypes. Herein, we describe two cases in which PPTA aneurysms were treated with stent-assisted coil embolization, considering the anatomical features.

\section{Case Presentations}

Both patients provided written informed consent to publish information about their conditions, treatments, and outcomes.

\section{Case 1}

A 65-year-old woman presented to a clinic and head magnetic resonance angiography (MRA) revealed an unruptured right PPTA aneurysm incidentally (Fig. 1A and 1B). Digital subtraction angiography (DSA) revealed that the 

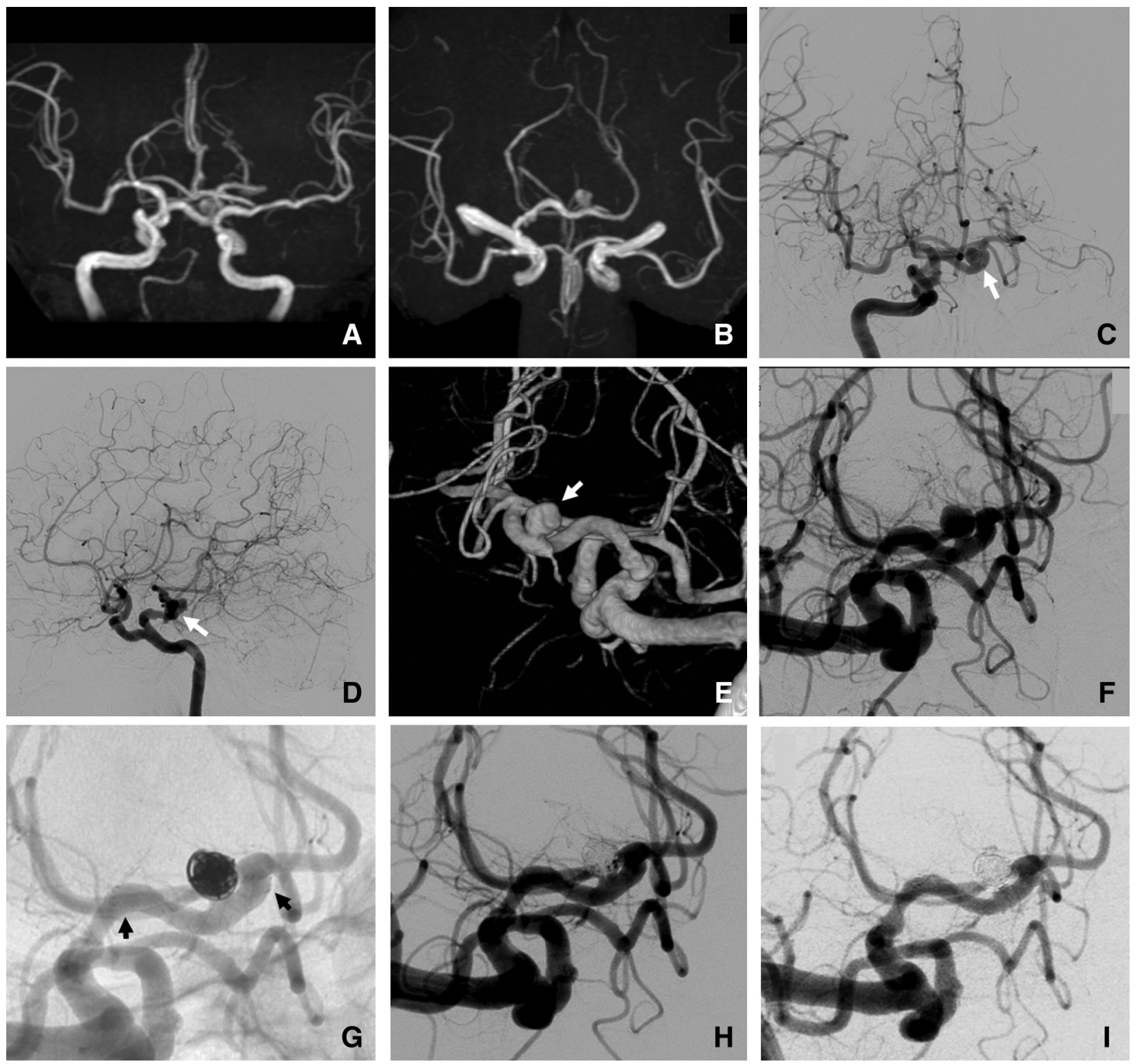

Fig. 1 Imaging results from case 1. MRA revealed an unruptured right PPTA aneurysm and showed that the proximal BA and bilateral Pcom were hypoplastic (A, B). Conventional and 3D-DSA showed a saccular aneurysm (white arrow) at the PPTA-BA bifurcation (C: A-P view, D: lateral view, E: inverted image of working angle from posteroinferior view). A stent (black arrow) was deployed from the BA to the PPTA and coil

embolization was performed, and achieved aneurysm occlusion with a slight neck remnant (F-H: working angle from anterosuperior view). Follow-up DSA at 1 year confirmed that the aneurysm had no recurrence (I). BA: basilar artery; DSA: digital subtraction angiography; MRA: magnetic resonance angiography; Pcom: posterior communicating artery; PPTA: persistent primitive trigeminal artery

PPTA originated from the $\mathrm{C} 4$ segment of the ICA, and the aneurysm was located at the PPTA-BA bifurcation (Fig. 1C-1E). MRA showed that the proximal BA and bilateral posterior communicating artery (Pcom) were hypoplastic (Fig. 1A and 1B), and the PPTA ran lateral to the dorsum sellae, indicating that the PPTA was lateral and Saltzman type 1 . The neck and dome widths of the aneurysm were $4.1 \mathrm{~mm}$ and $6.5 \mathrm{~mm}$, respectively.

\section{Endovascular treatment}

Because the PPTA was Saltzman type 1 with a hypoplastic vertebral artery (VA)-BA system, and the aneurysm was widenecked, treatment with a stent-assisted technique was selected considering the risk of ischemia from balloon inflation, and the risk of coil deviation to the parent PPTA after balloon deflation (Fig. 1F). The patient was administered aspirin $(100 \mathrm{mg} / \mathrm{d})$ and clopidogrel $(75 \mathrm{mg} / \mathrm{d})$ for 14 days before the procedure. 

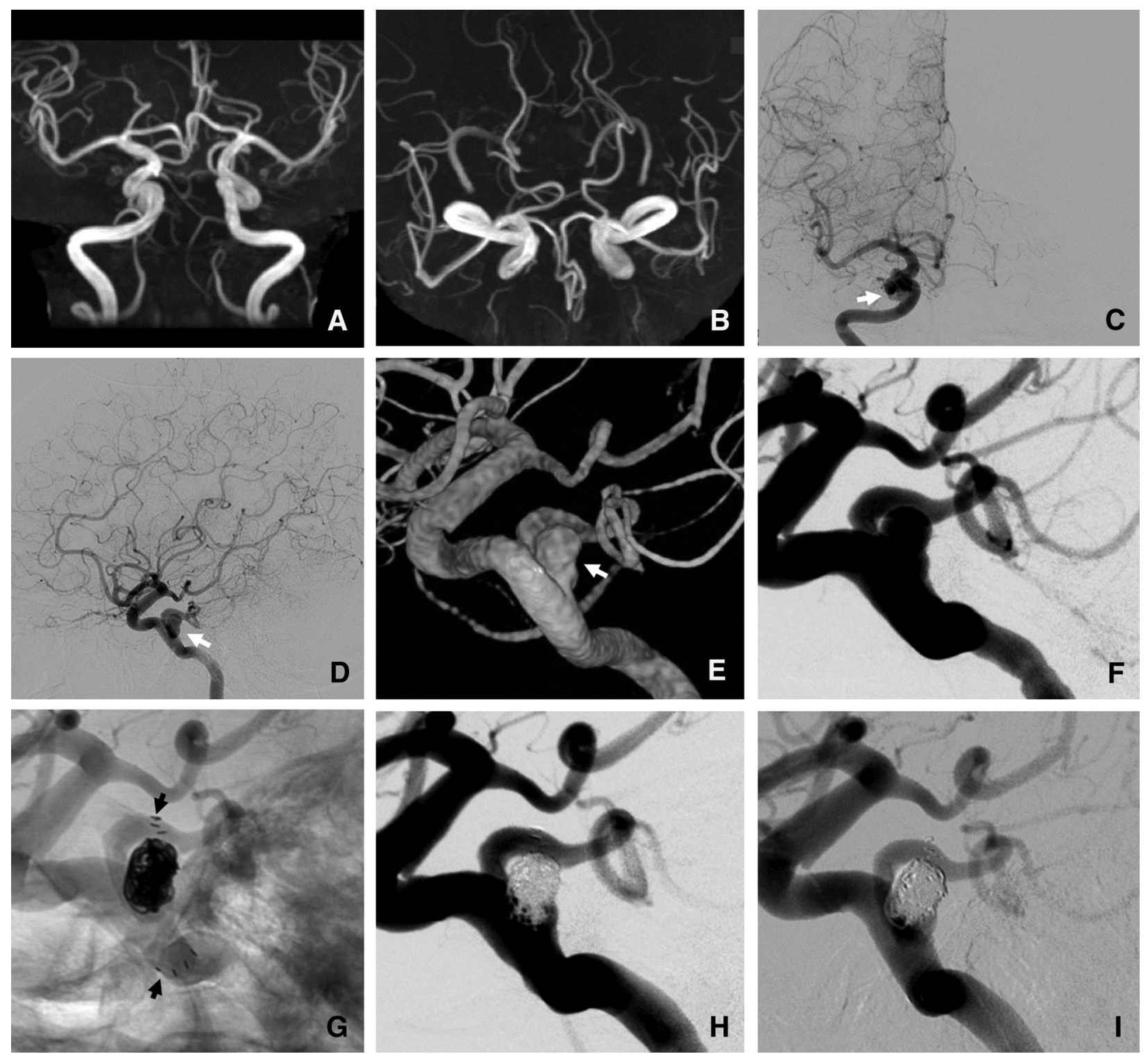

Fig. 2 Imaging results from case 2. MRA revealed an unruptured right PPTA aneurysm and showed that the lower BA was hypoplastic, while the bilateral Pcoms were developed (A, B). Conventional and 3D-DSA showed a saccular aneurysm (white arrow) at the ICA-PPTA bifurcation (C: A-P view, D: lateral view, E: image of working angle). A stent (black arrow) was deployed from the PPTA to the ICA and coil

embolization was performed, and achieved partial aneurysm occlusion with a neck remnant $(\mathrm{F}-\mathrm{H})$. Follow-up DSA at 1 year confirmed that the neck remnant remained but seemed to have slightly improved (I). BA: basilar artery; DSA: digital subtraction angiography; ICA: internal carotid artery; MRA: magnetic resonance angiography; Pcom: posterior communicating artery; PPTA: persistent primitive trigeminal artery

An 8-Fr Launcher guide catheter (Medtronic, Irvine, CA, USA) was inserted into the right ICA under general anesthesia. A 6-Fr Cerulean DD6 catheter (Medikit, Tokyo, Japan) was then positioned above the petrous segment of the ICA to provide distal access, and a Headway 17 microcatheter (MicroVention/Terumo, Tustin, CA, USA) was navigated into the $\mathrm{P} 1$ segment of the right posterior cerebral artery (PCA) via the PPTA. An Echelon 14 microcatheter (Medtronic) was then inserted into the aneurysm.

Coil embolization was performed with a semi-jailing technique. An LVIS Jr stent $(3.5 \mathrm{~mm} \times 23 \mathrm{~mm}$; MicroVen-
tion/Terumo) was partially deployed from the BA just proximal to the superior cerebellar artery (SCA) to the neck of the aneurysm, and the aneurysm was embolized with six Target coils (total length, $54 \mathrm{~cm}$; Stryker, Kalamazoo, MI, USA). The remainder of the stent was then deployed (Fig. 1G). Postoperative DSA revealed aneurysm occlusion with a slight neck remnant (Fig. 1H).

\section{Postprocedural course}

The patient was discharged on postoperative day 4 without neurological deficits. Follow-up DSA performed 1 year 


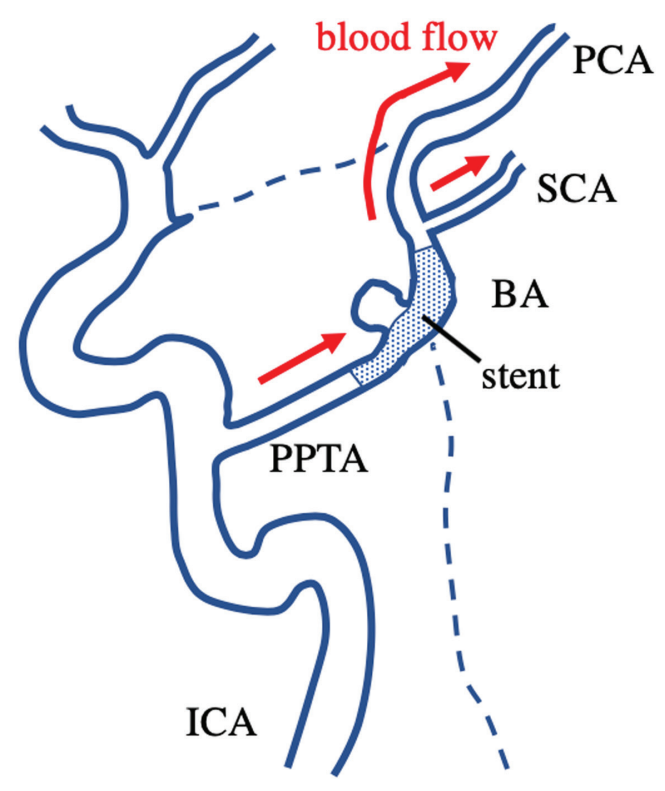

Case 1

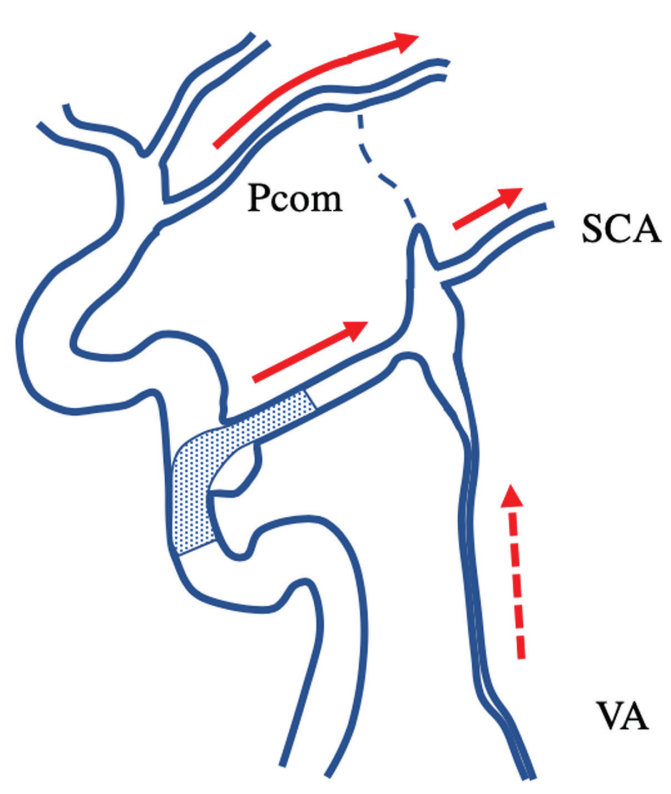

Case 2

A

B

Fig. 3 Scheme of current cases. Case 1 was a PPTA-BA aneurysm classified as Saltzman type 1 with a hypoplastic VA-BA system (A). Case 2 was an ICA-PPTA aneurysm classified as Saltzman type 2 with a hypoplastic VA-BA system (B). These cases are better to treat with a stent-assisted technique. BA: basilar artery; ICA: internal carotid artery; PPTA: persistent primitive trigeminal artery; VA: vertebral artery

after the procedure confirmed that the aneurysm had no recurrence (Fig. 1I).

\section{Case 2}

A 69-year-old woman presented to a clinic and head MRA revealed an unruptured right PPTA aneurysm incidentally (Fig. 2A and 2B). DSA revealed that the PPTA originated from the $\mathrm{C} 4$ segment of the ICA, and the aneurysm was located at the ICA-PPTA bifurcation (Fig. 2C-2E). MRA showed that the proximal BA was hypoplastic, although bilateral Pcoms were adequately developed (Fig. 2A and 2B), and the PPTA ran lateral to the dorsum sellae. Thus, the PPTA was classified as lateral and Saltzman type 2. The neck and dome widths of the aneurysm were $4.9 \mathrm{~mm}$ and $7.8 \mathrm{~mm}$, respectively.

\section{Endovascular treatment}

Because the PPTA was Saltzman type 2, but the VA-BA system was hypoplastic and the aneurysm was widenecked, treatment with a stent-assisted technique was selected (Fig. 2F). The patient was administered aspirin $(100 \mathrm{mg} / \mathrm{d})$ and clopidogrel $(75 \mathrm{mg} / \mathrm{d})$ for 21 days before the procedure. Because the patient was nonresponsive to clopidogrel, the drug was switched to prasugrel from the day before the procedure (the patient took $20 \mathrm{mg} / \mathrm{d}$ the day before and $3.75 \mathrm{mg} / \mathrm{d}$ on the day of the procedure).

A 7-Fr Roadmaster guide catheter (Goodman, Aichi, Japan) was inserted into the cervical segment of the right ICA under general anesthesia. A Prowler Select Plus microcatheter (Johnson \& Johnson, New Brunswick, NJ, USA) was navigated into the PPTA trunk, and a Headway 17 microcatheter was inserted into the aneurysm.

Coil embolization was performed with a jailing technique. An Enterprise2 stent $(4.0 \mathrm{~mm} \times 23 \mathrm{~mm}$; Johnson \& Johnson) was deployed from the PPTA to the petrous segment of ICA to cover the neck of the aneurysm, and the aneurysm was embolized with nine Target coils (total length, $55 \mathrm{~cm}$ ) (Fig. 2G). Postoperative DSA revealed partial aneurysm occlusion with a neck remnant (Fig. 2H).

\section{Postprocedural course}

The patient was discharged on postoperative day 7 without neurological deficits. Follow-up DSA performed 1 year after procedure confirmed that the neck remnant remained but it seemed to have slightly improved (Fig. 2I). 
Table 1 Summary of existing case reports of stent-assisted coil embolization for PPTA aneurysms

\begin{tabular}{|c|c|c|c|c|c|c|c|c|c|c|}
\hline $\begin{array}{l}\text { Authors } \\
\text { Year }\end{array}$ & $\begin{array}{l}\text { Age } \\
\text { (y) }\end{array}$ & Sex & Side & Location & $\begin{array}{l}\text { Saltzman } \\
\text { type }\end{array}$ & $\begin{array}{l}\text { VA-BA } \\
\text { system }\end{array}$ & $\begin{array}{l}\text { Size }(\mathrm{mm}) \\
\text { Neck }(\mathrm{mm})\end{array}$ & $\begin{array}{l}\text { Stent, } \\
\text { Technique }\end{array}$ & Results & Complications \\
\hline $\begin{array}{l}\text { Murai et al. }{ }^{15} \\
2019\end{array}$ & 68 & $\mathrm{~F}$ & Lt & $\begin{array}{l}\text { ICA-PPTA } \\
\text { bifurcation }\end{array}$ & 1 & Hypoplastic & $\begin{array}{c}12.7 \times 8.6 \\
6.8\end{array}$ & $\begin{array}{l}\text { Neuroform, } \\
\text { trans-cell }\end{array}$ & $\mathrm{CO}$ & None \\
\hline $\begin{array}{l}\text { Zenteno et al. }{ }^{20} \\
2018\end{array}$ & 33 & $\mathrm{~F}$ & Rt & $\begin{array}{l}\text { PPTA-BA } \\
\text { bifurcation }\end{array}$ & 1 & Hypoplastic & $\begin{array}{l}\text { N/A } \\
\text { N/A }\end{array}$ & $\begin{array}{c}\text { Neuroform3, } \\
\text { trans-cell }\end{array}$ & $\mathrm{CO}$ & None \\
\hline $\begin{array}{l}\text { Ajeet et al. }{ }^{19} \\
2016\end{array}$ & 44 & $\mathrm{~F}$ & Lt & PPTA trunk & 3 & Adequate & $\begin{array}{c}9 \times 9 \times 6 \\
N / A\end{array}$ & $\begin{array}{l}\text { Neuroform EZ, } \\
\text { trans-cell }\end{array}$ & $\mathrm{CO}$ & None \\
\hline $\begin{array}{l}\text { Chen et al. }{ }^{17} \\
2015\end{array}$ & 69 & $\mathrm{~F}$ & $\mathrm{Lt}$ & $\begin{array}{l}\text { ICA-PPTA } \\
\text { bifurcation }\end{array}$ & 1 & Hypoplastic & $\begin{array}{c}12 \times 12 \times 10 \\
\text { N/A }\end{array}$ & $\begin{array}{l}\text { Jostent, } \\
\text { stent only }\end{array}$ & $\mathrm{CO}$ & None \\
\hline $\begin{array}{l}\text { Zhao et al. }{ }^{18} \\
2005\end{array}$ & 28 & $\mathrm{~F}$ & Rt & $\begin{array}{l}\text { ICA-PPTA } \\
\text { bifurcation }\end{array}$ & 2 & Adequate & $\begin{array}{c}\operatorname{Max} 3.2 \\
4.0\end{array}$ & $\begin{array}{l}\text { Neuroform, } \\
\text { trans-cell }\end{array}$ & $\mathrm{CO}$ & None \\
\hline $\begin{array}{l}\text { Mohammed } \\
\text { et al. }{ }^{16} \\
2002\end{array}$ & 58 & $\mathrm{~F}$ & Rt & $\begin{array}{l}\text { ICA-PPTA } \\
\text { bifurcation }\end{array}$ & 3 & Adequate & $\begin{array}{c}4.5 \times 5 \times 5 \\
4.5\end{array}$ & $\begin{array}{l}\text { coronary stent, } \\
\text { trans-cell }\end{array}$ & $\mathrm{CO}$ & None \\
\hline Current case 1 & 65 & $\mathrm{~F}$ & Rt & $\begin{array}{l}\text { PPTA-BA } \\
\text { bifurcation }\end{array}$ & 1 & Hypoplastic & $\begin{array}{c}\operatorname{Max} 6.5 \\
4.1\end{array}$ & $\begin{array}{l}\text { LVIS, } \\
\text { semi-jailing }\end{array}$ & $\mathrm{CO}$ & None \\
\hline Current case 2 & 69 & $\mathrm{~F}$ & Rt & $\begin{array}{l}\text { ICA-PPTA } \\
\text { bifurcation }\end{array}$ & 2 & Hypoplastic & $\begin{array}{c}\text { Max } 7.8 \\
4.9\end{array}$ & $\begin{array}{l}\text { Enterprise2, } \\
\text { jailing }\end{array}$ & NR & None \\
\hline
\end{tabular}

Four cases were classified as Saltzman type 1, and various stents were used. No cases had complications. BA: basilar artery; CO: complete occlusion; F: female; ICA: internal carotid artery; Lt: left; NR: neck remnant; PPTA: persistent primitive trigeminal artery; Rt: right; VA: vertebral artery 


\section{Discussion}

PPTA frequently coexists with other vascular anomalies, such as aneurysms, moyamoya disease, carotid-cavernous fistulas, and arteriovenous malformations. ${ }^{3,4)}$

Some authors have reported that PPTA is associated with an increased prevalence of aneurysms $(14 \%-32 \%), 5,6)$ but others have reported that the prevalence of aneurysms in patients with PPTA is unremarkable $(2 \%-3 \%))^{7)}$ PPTA aneurysms can occur at the PPTA-ICA bifurcation, along the PPTA trunk, or at the PPTA-BA bifurcation, with a frequencies of $42 \%, 38 \%$, and $12 \%$, respectively. ${ }^{8}$ Rupture of such aneurysms leads to direct carotid-cavernous fistulas or subarachnoid hemorrhage. ${ }^{1,4)}$

Cases of PPTA are classified as lateral type or medial type according to the anatomical properties of the artery. ${ }^{9}$ In medial-type PPTAs, the artery projects through or over the dorsum sellae before connecting to the BA. In lateraltype PPTAs, the artery projects along the dorsum sellae after passing between the trigeminal and abducens nerves, which may cause nerve compression resulting in trigeminal neuralgia or ocular motility disorder. ${ }^{10,11)}$

Cases of PPTA can also be anatomically classified according to Saltzman types. ${ }^{2,12}$ In type 1, the Pcom and the proximal BA are usually hypoplastic, and the PPTA connects to the $\mathrm{BA}$ between the anterior inferior cerebellar artery and the SCA orifice. The PPTA provides blood flow to the distal BA and PCA. In Saltzman type 2, the PPTA connects to the BA at a location proximal to the SCA orifice. In adequately developed Pcoms, posterior circulation is less dependent on the PPTA than it is in Saltzman type 1. Saltzman type 3 is a combination of types 1 and 2, and the PPTA provides blood flow to the bilateral SCA and contralateral PCA, while the ipsilateral PCA receives its blood through the Pcom. Whether the different Saltzman types are associated with different prevalences of PPTA aneurysms is unknown.

Because PPTA aneurysms are often deeply positioned near the cranial nerve and perforating vessels, surgical approaches are considered difficult. Numerous studies have examined the feasibility of endovascular therapy, ${ }^{13,14)}$ and simple technique or double catheter technique can be selected depending on the shape of aneurysms. But as with typical wide-necked aneurysms, wide-necked PPTA aneurysms usually necessitates using adjunctive techniques such as stent- or balloon-assisted techniques. ${ }^{13,15)}$ When considering the strategies for treating PPTA aneurysms, operators should focus on the lesion site and anatomical features, that is Saltzman type and VA-BA system development. For
ICA-PPTA aneurysms, ischemia of the anterior and posterior circulation will occur during the inflation of balloon in Saltzman type 1, especially in cases with a hypoplastic VA-BA system. Therefore, stents are the better choice in these cases, although stents make it difficult to approach to the distal ICA. With the PPTA trunk or PPTA-BA aneurysm, the risk of ischemia of the anterior circulation can be avoided; however, the risk of ischemia of the posterior circulation cannot be avoided when using a balloon in cases that are Saltzman type 1 or have a hypoplastic VA-BA system. Therefore, stents may be the more appropriate choice in these cases. In Saltzman type 2 cases, the selection of a balloon or a stent depends on the VA-BA system development. A stent is more suitable for inadequately developed VA-BA systems, while a balloon may be used for adequately developed VA-BA systems. For adequately developed VA-BA systems, the PPTA can be sacrificed in all aneurysm cases (a balloon occlusion test should be performed before treatment), and also it could be considered to approach through the developed VA. In the cases described here, case 1 was classified as a Saltzman type 1 PPTA-BA wide-necked aneurysm. Accordingly, we treated the patient using a stent (Fig. 3A). Case 2 was classified as a Saltzman type 2 ICA-PPTA wide-necked aneurysm. The VA-BA system was hypoplastic and a stent was deployed successfully without stopping blood flow (Fig. 3B). In the literature, there are six reported incidence of stent-assisted treatments for PPTA aneurysms (Table 1). ${ }^{15-20)}$ Including the two cases presented herein, five aneurysms were at the ICA-PPTA, one was at the PPTA trunk, and two were at the PPTA-BA. Four cases were classified as Saltzman type 1; four were classified as types 2 or 3 . Murai et al. ${ }^{15)}$ reported that the Allcock test or balloon occlusion test are important to assess the anterograde flow in the BA and select the most appropriate treatment strategy. Mohammed et al. ${ }^{16)}$ reported a case in which a stent was deployed from the distal to the proximal ICA for an ICA-PPTA aneurysm with jailing of the PPTA in a patient with an adequately developed VA-BA system. Most reported cases of stent-assisted treatment of a PPTA aneurysm achieved complete aneurysm occlusion without complications, including ischemic events. This indicates that the stent-assisted technique is a useful endovascular treatment for PPTA aneurysm.

\section{Conclusion}

This report describes two cases in which PPTA aneurysms were successfully treated with stent-assisted coil 
embolization. The anatomical features of PPTA variants must be considered when treating PPTA aneurysms.

\section{Acknowledgment}

We would like to thank Edanz Group (www.edanzediting. com/ac) for English language editing.

\section{Disclosure Statement}

The authors have no conflicts of interest. This research received no specific grant from any funding agency in the public, commercial, or not-for-profit sectors.

\section{References}

1) Agnoli AL: Vascular anomalies and subarachnoid haemorrhage associated with persisting embryonic vessels. Acta Neurochir (Wien) 1982; 60: 183-199.

2) O’uchi E, O’uchi T: Persistent primitive trigeminal arteries (PTA) and its variant (PTAV): analysis of 103 cases detected in 16,415 cases of MRA over 3 years. Neuroradiology 2010; 52: 1111-1119.

3) Hou K, Ji T, Guo Y, et al: The coexistence of persistent primitive trigeminal artery, moyamoya disease, and multiple intracranial aneurysms: a case report and literature review. World Neurosurg 2019; 124: 313-318.

4) Guglielmi G, Viñuela F, Dion J, et al: Persistent primitive trigeminal artery-cavernous sinus fistulas: report of two cases. Neurosurgery 1990; 27: 805-808; discussion 808809.

5) George AE, Lin JP, Morantz RA: Intracranial aneurysm on a persistent primitive trigeminal artery. Case report. $J \mathrm{Neu}$ rosurg 1971; 35: 601-604.

6) Alcalá-Cerra G, Tubbs RS, Niño-Hernández LM: Anatomical features and clinical relevance of a persistent trigeminal artery. Surg Neurol Int 2012; 3: 111.

7) Cloft HJ, Razack N, Kallmes DF: Prevalence of cerebral aneurysms in patients with persistent primitive trigeminal artery. J Neurorsurg 1999; 90: 865-867.

8) Takemoto K, Iwaasa M, Nishikawa W, et al: Coil embolization to the ruptured aneurysm of basilar artery-persistent primitive trigeminal artery junction. Jpn J Neurosurg 2005; 14: 706-712.
9) Ohshiro S, Inoue T, Hamada Y, et al: Branches of the persistent primitive trigeminal artery--an autopsy case. Neurosurgery 1993; 32: 144-148.

10) Ishikawa $T$, Yamaguchi $K$, Anami $H$, et al: Treatment of large or giant cavernous aneurysm associated with persistent trigeminal artery: case report and review of literature. World Neurosurg 2017; 108: 996.e11-996.e15.

11) Ladner TR, Ehtesham M, Davis BJ, et al: Resolution of trigeminal neuralgia by coil embolization of a persistent primitive trigeminal artery aneurysm. BMJ Case Rep. 2013; 2013: bcr2013010703.

12) Saltzman GF: Patent primitive trigeminal artery studied by cerebral angiography. Acta radiol 1959; 51: 329-336.

13) Kai Y, Ohmori Y, Watanabe M: Coil embolization of an aneurysm located at the trunk of the persistent primitive trigeminal artery. Neurol Med Chir 2011; 51: 361-364.

14) Schlamann M, Doerfler A, Schoch B, et al: Balloon-assisted coil embolization of a posterior cerebral artery aneurysm via a persistent primitive trigeminal artery: technical note. Neuroradiology 2006; 48: 931-934.

15) Murai S, Sugiu K, Hishikawa T, et al: Endovascular treatment for unruptured aneurysm associated with persistent primitive trigeminal artery: a case report and literature review. Acta Neurochir (Wien) 2019; 161: 407-411.

16) Mohammed MI, Sandhu JS, Wakhloo AK: Stent-assisted coil placement in a wide-necked persistent trigeminal artery aneurysm with jailing of the trigeminal artery: a case report. AJNR Am J Neuroradiol 2002; 23: 437-441.

17) Chen WH, Tsai TH, Shen SC, et al: A case of giant thrombosed persistent primitive trigeminal artery aneurysm presenting with trigeminal neuralgia and successfully treated by a covered stent: case report and review of literature. Clin Neuroradiol 2015; 25: 207-210.

18) Zhao QP, Li TL, Duan CZ, et al: Combined neuroform intracranial stent and bioactive matrix detachable coil for embolization of a broad-necked persistent primitive trigeminal artery aneurysm. A case report. Interv Neuroradiol 2005; 11: 63-68.

19) Ajeet G, John D: Dual stent-assisted coil embolization for fusiform aneurysm arising from persistent trigeminal artery. Neurointervention 2016; 11: 131-134.

20) Zenteno M, Lee A, Moscote-Salazar LR: Rupture of persistent primitive trigeminal artery-basilar artery aneurysm managed with stent-assisted coiling. Asian J Neurosurg 2018; 13: 817-821. 